\title{
Ho Nam Chang Special Issue: Life of a great biochemical engineer and his life-time contribution to high cell density culture
}

\author{
Sang Yup Lee
}

Published online: 30 June 2009

(c) Springer-Verlag 2009

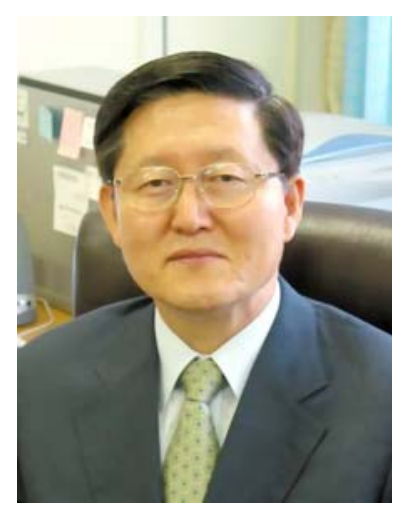

Professor Ho Nam Chang, Department of Chemical and Biomolecular Engineering, KAIST, Daejeon, Korea

It is my great pleasure and honor to prepare this special issue for the retirement of Professor Ho Nam Chang, a great biochemical engineer of the last decades. He has been a leader in several important areas of biochemical engineering discipline and in particular in the field of high cell density culture. His life-time work has contributed to the successful industrialization of several bioproducts such as acrylamide and commercialization of new types of fermentors (bioreactors). He has also been a leader in AsiaPacific region in promoting biochemical engineering and biotechnology by setting up the high standard of research. Even though it is not possible to describe his great contributions in this short preface, I tried my best to summarize some of his important contributions.

\footnotetext{
S. Y. Lee $(\bowtie)$

Department of Chemical and Bimolecular Engineering,

College of Life Science and Bioengineering,

Korea Advanced Institute of Science and Technology (KAIST),

Daejeon 305-701, Korea

e-mail: leesy@kaist.ac.kr
}

\section{Background}

Ho Nam Chang was born on October 9, 1944 at Namhae Island in the South Sea of Korean Peninsula. He attended Namhae Elementary School (1951-1957) and moved to Busan, the second largest city in Korea for his Kyungnam Middle School (1957-1960) and Kyungnam High School education (1960-1963). In 1963 he successfully entered Seoul National University with the highest honor to major in chemical engineering, the most popular subject in those days. After finishing 4 years of college, he joined Korean military duty service for 3 years (1967-1970).

Right after his military service he went to Stanford University with DeWitt Wallace Scholarship thanks to US 4star General Van Fleet, who once stationed in Korea as Chief Commander of UN forces. After 1 year Master's degree in Chemical Engineering, he pursued his $\mathrm{PhD}$ degree (title: Adhesion and aggregation of blood platelets) under the supervision of Professor Channing R. Robertson. After 1 year postdoctoral study in enzyme engineering at Iowa State University (Professor Peter J. Reilly), he returned to Korea to assume an assistant professorship in the Department of Bioscience and Bioengineering at Korea Advanced Institute of Science (KAIS) in 1976. However, in 1977 he moved to Department of Chemical Engineering and was promoted to associate professor in 1978 and professor in 1982.

His early research interest was application of anaerobic packed-bed system (developed by Professor P. L. McCarty at Stanford University) to the treatment of high strength industrial waste water. Upon moving to Chemical Engineering Department he studied transport phenomena of turbulence promoters in membrane modules and progressively moved to high cell density cultures of microbial cells, later plant cells and animal cells where he obtained many world-record breaking results. Since then he was widely 
known as the expert in high cell density culture systems. In 1990 he obtained Bioprocess Engineering Research Center from Korea Science and Engineering Foundation (KOSEF) where he served as Director for the next 10 years.

\section{Early years (1976-1984)}

The knowledge or expertise he gained during his 4 years of Stanford $\mathrm{PhD}$ and 1 year of Iowa State University postdoc was a lot of fluid mechanics-oriented transport phenomena, medical biochemistry, enzyme engineering and bioreactor process engineering. When he joined Department of Bioscience and Biological Engineering, Korea Advanced Institute of Science (KAIS, older name of current KAIST) was that the student he trained should get a job in the industry which agrees to refund the student's educational expense at KAIS. This was quite a severe requirement for the department faculty members because the bio-industry in Korea was able to find necessary manpower elsewhere without any trouble. Because of this reason he started an environmental research on high strength wastewater treatment by spending time at Department of Civil Engineering at University of Illinois at Urbana Champaign with help from Professor E. S. K. Chian. One year later he moved to Department of Chemical Engineering of KAIS and the student-payback problem was solved since chemical industries wanted to hire KAIS students regardless of educational expense refund to KAIS.

In 1979 KAIS started its own PhD program and Dr. I. H. Kim (LG-Chem, now at Chungnam National Univ.) was the first PhD student of H. N. Chang. Kim tried to improve the efficiency of free enzyme by facilitate contact between substrate (small molecule) and enzyme (large molecule) separated by ultrafiltration membrane. Of course convection-driven mixing was much more efficient than diffusion alone [1, 2]. The first $\mathrm{PhD}$ work of Kim was quite a success since it meets the KAIST requirement that a part of the $\mathrm{PhD}$ thesis must be published in a well-known international journal like AIChE J.

The other works during this period were to solve mass transfer problems in turbulence promoter (also called as spacer) in membrane modules. During this period H. N. Chang attracted many brightest students from the class and they pursued their doctoral work at Caltech, MIT and other US universities. They are now Professors at SNU, KAIST and POSTEC [3-5].

\section{High cell density culture (HCDC) (1984-2009)}

When H. N. Chang left Iowa State in 1976, Professor P. J. Reilly advised H. N. Chang not to work on fermentation, although he received his $\mathrm{PhD}$ under Professor Humphrey at U. Penn by working on gluconic acid fermentation. H. N. Chang accepted this advice and educated his first $\mathrm{PhD}$ Kim to work on enzyme engineering. However, after his first $\mathrm{PhD}$ he ran into a difficulty of finding a proper topic for his second $\mathrm{PhD}$. H. N. Chang started to think about expanding his research into other areas such as fermentation. At this time Japan succeeded in amino acid conversion using immobilized enzyme. Rather than following the foreign (Japanese) trends, he started to realize that fermentation is an area to which he should devote himself, although he did not have an in-depth knowledge in fermentation at that time. What area of fermentation could he enter in order for his second $\mathrm{PhD}$ student Chang Woo Lee to start his $\mathrm{PhD}$ thesis work?

Although H. N. Chang did not have a much knowledge in microbial physiology, one thing he was sure that bioreactor operation in biotechnology was batch or fed-batch (much lower productivity), that is different from conventional petrochemical industry's continuous high productivity operation using catalyst. When he was thinking of taking this challenging task as his life-long research subject, he happened to find MIT Professor C. L. Cooney's article on "Bioreactors: Design and Operation (Science, 1983)" where the importance of high cell density culture was well emphasized [6].

We can identify the most important three elements in improving productivities of a bioreactor: strain productivity $\left(q_{p / x}\right)$, cell mass $(X)$ and oxygen transfer rate (OTR) of bioreactor. At this time in 1983 Prof. Chang thought that he could contribute to the advancement of low productivity batch or fed-batch fermentation process to high cell density continuous culture (HCDC). Already an earlier version of membrane cell recycle system for ethanol production became available by P. L. Rogers of South Wales [7]. C. W. Lee and H. N. Chang [8] studied HCDC ethanol kinetics and proposed a way of controlling biomass in a bioreactor by adjusting substrate concentration, dilution and bleed rates. Lee and Chang also achieved $210 \mathrm{~g} / \mathrm{L}$ of biomass $(X)$ with productivity of $85 \mathrm{~g} / \mathrm{L} / \mathrm{h}$ using $14 \%$ glucose solution based on $100 \%$ substrate utilization. A $65 \mathrm{~g} / \mathrm{L}$ of ethanol titer was achieved, which accounts for $91 \%$ yield of a theoretical maximum of $71.4 \mathrm{~g} / \mathrm{L}$. H. N. Chang extended this work to an aerobic culture of Aspergillus niger for citric acid production using dual hollow fiber bioreactor where oxygen from a silicon hollow fiber can be supplied to a nearby substrate containing hollow fibers [9].

All these HCDC work showed a remarkable stability for a long-term study with several ten times productivity but always having a lower product titer. Furthermore, all these systems were carried out in a lab-scale with very little hope of scale-up. 
After achieving many goals of $X$ up to $145 \mathrm{~g} / \mathrm{L}$ in the HCDC culture of recombinant $E$. coli using hollow fiber cell recycle bioreactors [10], H. N. Chang tried to change external cell recycle into internal cell system that did not work well. He tried to achieve his goal using immobilized cells to produce lactic acid, but he found out that suspended cell culture was much more superior to that of the immobilized cell systems.

H. N. Chang and his group cultivated Alcaligenes eutrophus cells by glucose fed-batch to a high cell density of $164 \mathrm{~g} / \mathrm{L}$ to produce poly(3-hydroxybutyric acid) (PHB) from glucose by the automatic fed-batch culture using pure oxygen [11]. The maximum PHB content reached $76 \%$ of dry cell weight and the productivity was $2.42 \mathrm{~g} / \mathrm{L} / \mathrm{h}$ with the yield of $0.3 \mathrm{~g} \mathrm{PHB} / \mathrm{g}$-glucose. I myself have started on polyhydroxyalkanoates in collaboration with him [12] using various metabolic engineering strategies.

\section{Multi-stage-continuous (MSC)-HCDC}

H. N. Chang pursued his single stage continuous HCDC further to improve product titer by adding an extra HCDC unit. Kwon et al. [13] operated 2-stage-continuous (SC)HCDC for lactic acid production and $\mathrm{Oh}$ et al. [14-16] developed depth filter perfusion system for animal cell entrapment and carried out 2SC-HCDC for monoclonal antibody production. The above $2 \mathrm{SC}-\mathrm{HCDC}$ yielded very encouraging results of increased product titer with maintaining nearly a productivity of 1SC-HCDC. This work naturally led $\mathrm{H}$. N. Chang to believe multi-stage continuous HCDC: what is the end of many stages of HCDC? He found out that MSC-HCDC may accomplish that of fedbatch titer with much higher productivity [17].

In the case of monoclonal antibody production seven HCDC units are necessary for product titer to reach that of fed-batch. Each HCDC unit is equipped with cell recycling device of upflow packed-bed biofilter that might capture 95\% of the cells with minimum pressure drop. Pure oxygen is generated from pressure swing adsorption method and regenerated by removing $\mathrm{CO}_{2}$ from fermentation off-gas [17-19].

\section{Industrialized processes}

H. N. Chang worked with Dongsuh Chemical Company in Ulsan, Korea for biological production of acrylamide from acrylonitrile produced by Dongsuh (1988-1996). He developed a batch process rather than the immobilized cell process by Nitto in Japan. Now Dongsuh produces $5,000-10,000$ tons of acrylamide/year.

H. N. Chang's second commercialization effort started with his venture of treating apartment food-waste generated by kitchen disposer. He succeeded a large-scale food- waste treatment of 100 apartments and City of Seoul has been conducting a larger scale of 500 apartment units to test whether this technology is applicable to 10 million apartment household units in Korea. Hopefully Korean government will allow Korean people to use kitchen garbage disposer with this special collective food-waste treatment unit.

\section{VFA (volatile fatty acids)-platform for fuels and chemicals}

Based on his research experience on anaerobic digestion of high strength organic waste and the utilization efforts of volatile fatty acids-intermediate product to biogas generation, H. N. Chang started volatile fatty acid platform to make biofuels such as 6:1:3 ratios of ethanol, propanol and butanol by adding $2 \mathrm{H}_{2}$ to acetic, propionic, butyric acids [20]. H. N. Chang sees an advantage of using his MSCHCDC technology in the acidification of various organic wastes. New chemical platform can be made starting from the VFAs and its derivatives. He hopes that this platform can replace much of current sugar platform based on glucose and xylose.

\section{Other activities}

Upon his returning to Korea in 1976 he got involved in many societies such as Korea Institute of Chemical Engineers, Microbial Societies and attended AIChE and ACS meetings. In 1983 he served as Secretary General in organizing 3rd Asia-Pacific Chemical Engineers meeting to become the first and most successful meeting of its kind in Korea. He played a key role in founding Asia-Pacific Biochemical Engineering Meeting (APBioCheC) in 1990. After 20 years' of its existence APBioCheC will be transformed to Asian Federation of Biotechnology (http:// www.AOFB.org), a similar organization to that of EFB in Europe since 2010.

He served as Provost at KAIST from 1995 to 1998 and served as the Presidential Council on Science and Technology under Korean President Y. S. Kim. During the years of 1994-2002 he served as in Korea Science and Engineering Foundation, Korea Research Council and Korea Council of Fundamental Science and Technology.

$\mathrm{He}$ received many prizes including two academic awards of Chemical Engineers and Korean Society for Biotechnology and Bioengineers. In 1997 he received the most prestigious Korea Engineering award (Presidential) and in the same year received Asia-Pacific Biochemical Engineering award from its Beijing meeting. He now serves as advisory board members in Biotechnology and Bioengineering, and several foreign journals. He is now members of National Academy of Engineering Korea 
(Vice President: 2006-2008) and Korea Academy of Science and Technology.

He has directed $45 \mathrm{PhDs}$ in biochemical engineering and some transport phenomena and $100 \mathrm{MS}$ students during his Professorship at KAIST from 1976 till date. He has published 235 papers in international journals, and 147 papers in Korean journals. These papers received about 3,800 citations from various journals. He served as President of Stanford Association of Korea during 2001-2003. His wife Youngsook Park is also a Professor of Nutrition at Soonchunhyung University and he has two granddaughters from his only daughter Suhie and son-in-law Sunyoung Kwon.

This special issue contains papers contributed by the authors who were former students of H. N. Chang and his colleagues around the world. I would like to thank the authors who have enthusiastically supported for preparing this special issue. Also, I want to thank Professor Hyun Gyu Park at KAIST, who has helped me on organizing this issue. It is hoped that this special issue will be a timely recognition of a great biochemical engineer, who has contributed his entire life to the advancement of this field. I believe that his retirement is not the end of his activities, and will be a new-start of his great career.

Thank you, Professor Ho Nam Chang, for your great contribution to the advancement of biochemical engineering and biotechnology!

\section{References}

1. Kim IH, Chang HN (1982) AIChE J 28:645-651

2. Kim IH, Chang HN (1983) AIChE J 29:910-914

3. Chang HN (1982) AIChE J 28:1030-1032

4. Kang IS, Chang HN (1982) Int J Heat Mass Transfer 25:11671182

5. Park JK, Chang HN (1986) AIChE J 32:1937-1947

6. Cooney CL (1985) Science 219:728-733

7. Rogers PL, Lee KJ, Tribe DE (1980) Process Biochem 15:7-11

8. Lee CW, Chang HN (1987) Biotechnol Bioeng 29:1105-1112

9. Chung BH, Chang HN (1988) Biotechnol Bioeng 32:205-212

10. Lee YL, Chang HN (1990) Biotechnol Bioeng 36:330-337

11. Kim BS, Lee SC, Lee SY, Chang HN, Chang YK, Woo SI (1994) Biotechnol Bioeng 43:892-898

12. Lee SY, Yim KS, Chang HN, Chang YK (1994) J Biotechnol 32:203-211

13. Kwon SH, Yoo IK, Lee WG, Chang YK, Chang HN (2001) Biotechnol Bioeng 73:25-34

14. Oh DJ, Choi SK, Chang HN (1994) Biotechnol Bioeng 44:895-901

15. Lee JC, Kim DY, Oh DJ, Chang HN (2008) Biotechnol Bioprocess Eng 13:560-565

16. Lee JC, Kim DY, Oh DJ, Chang HN (2008) Biotechnol Bioprocess Eng 13:401-409

17. Chang HN, Kim BJ, Jeong CM, Kang JW, Park JK (2008) PCT/ KR 2008/000432 (WO 2008/091113 A1)

18. Shang LA, Jiang M, Ryu CH, Chang HN (2003) Biotechnol Bioeng 83:312-320

19. Chang HN, Kim BJ, Kang JW, Jeong CM, Kang JW, Park JK (2008) Biotechnol Bioprocess Eng 13:123-135

20. Holtzapple MT, Granada CB (2008) Appl Biochem Biotechnol 156:95-106 